\title{
A CONAPE como espaço de resistência social à ofensiva do Golpe
}

CONFEDERAÇÃO NACIONAL DOS TRABALHADORES EM EDUCAÇÃO

Brasília- DF, Brasil

A

Conferência Nacional Popular de Educação - CONAPE, realizada em Belo Horizonte entre os dias 26 e 28 de maio último, foi precedida de etapas municipais, intermunicipais, estaduais e distrital, reunindo milhares de educadores e educadoras, estudantes, pais, mães e ativistas sociais que lutam em defesa da educação pública, gratuita, universal, democrática, laica e de qualidade social.

A CONAPE é fruto da resposta engajada de inúmeras entidades da sociedade civil contra a tentativa do governo golpista, chefiado por Michel Temer, de silenciar os atores educacionais através da desconstituição do Fórum Nacional de Educação (FNE) e do adiamento e deslegitimação da Conferência Nacional de Educação (CONAE), ambos espaços institucionais para debate democrático das políticas educacionais, instituídos pela Lei 13.005, de 2014, que aprovou o Plano Nacional de Educação (PNE).

O objetivo do Decreto de 26 de abril de 2017 e da Portaria MEC n. 577/17, que, ilegalmente, romperam com os canais de diálogo permanente da sociedade com o Governo - por meio da CONAE e do FNE -, não é outro senão tornar essas instâncias subalternas ao Ministério da Educação, com o intuito de respaldar a adoção de medidas ultraliberais nos sistemas de ensino do País.

A CONAPE foi forjada para combater as (des)medidas de um governo usurpador. Um governo que ascende ao poder através de um golpe fomentado pelas elites política e econômica, em momento histórico onde imperam o obscurantismo e as contradições. E é sob a égide desse governo que os agentes de repressão ao crime e o Poder Judiciário se dizem empenhados em expurgar a corrupção do País. No mínimo curioso!

No cotidiano real da Pátria, o que se vê, de verdade, são assaltos à República e às riquezas do Brasil. O petróleo, os minérios, a água, as florestas e outros bens naturais são entregues dia após dia ao capital internacional. E os fundos públicos, inclusive a educação, também são alvos centrais da ganância capitalista.

A Emenda Constitucional ( federal ficará impedido de aportar novos recursos em políticas sociais, inclusive na educação. Também nas próximas duas décadas, caso a EC 95 não seja revogada, a educação (e a saúde) deixarão de contar com receitas vinculadas pela constituição federal (CF/1988) inviabilizando, por exemplo, o cumprimento da meta 20 do PNE, que prevê investimentos na ordem de 10\% do PIB em educação. 
Mesmo com uma história marcada por imensas restrições, o movimento social brasileiro conseguiu ao longo dos últimos trinta anos - período de vigência da última constituição promulgada - garantir direitos de acesso e permanência da população à educação pública, os quais estão sendo flexibilizados ou mesmo suprimidos numa velocidade nunca vista.

A CF/1988 representou um marco histórico em prol da garantia de direitos dos/as brasileiros/as e de luta pela igualdade social em nosso País. Diz o art. $3^{\text {o }}$ da constituição:

“Constituem objetivos fundamentais da República Federativa do Brasil:

I - construir uma sociedade livre, justa e solidária;

II - garantir o desenvolvimento nacional;

III - erradicar a pobreza e a marginalização e reduzir as desigualdades sociais e regionais;

IV - promover o bem de todos, sem preconceitos de origem, raça, sexo, cor, idade e quaisquer outras formas de discriminação".

A educação, particularmente, está situada como o primeiro direito social entre todos listados no art. $7^{\circ}$ da Carta Magna, in verbis:

"São direitos sociais a educação, a saúde, a alimentação, o trabalho, a moradia, o transporte, o lazer, a segurança, a previdência social, a proteção à maternidade e à infância, a assistência aos desamparados, na forma desta Constituição".

O mesmo protagonismo ficou registrado no Capítulo III, Seção I, que lista os direitos constitucionais afetos à educação (Art. 206 a 214 da CF/1988).

Para que o direito à educação fosse alcançado de forma satisfatória, os constituintes de 1988 mantiveram a vinculação constitucional de impostos retomada pela Emenda Calmon (Emenda Constitucional n. 24, de 1983), ampliando o percentual de investimento obrigatório da União de $13 \%$ para no mínimo 18\%, e mantendo em 25\% no mínimo a vinculação dos estados, DF e municípios sobre todos os impostos e transferências constitucionais:

Art. 212, CF/1988: "A União aplicará, anualmente, nunca menos de dezoito, e os Estados, o Distrito Federal e os Municípios vinte e cinco por cento, no mínimo, da receita resultante de impostos, compreendida a proveniente de transferências, na manutenção e desenvolvimento do ensino".

Registre-se, ainda, o compromisso do texto original da CF/1988 com a eliminação do analfabetismo e com a expansão do ensino superior, estratégico para o desenvolvimento nacional. 
desenvolverá esforços, com a mobilização de todos os setores organizados da sociedade e com a aplicação de, pelo menos, cinquenta por cento dos recursos a que se refere o art. 212 da Constituição, para eliminar o analfabetismo e universalizar o ensino fundamental.

Parágrafo único. Em igual prazo, as universidades públicas descentralizarão suas atividades, de modo a estender suas unidades de ensino superior às cidades de maior densidade populacional".

O advento da primeira experiência neoliberal no Brasil, durante a década de 1990, colocou em xeque vários direitos previstos na Carta Magna, entre eles, os educacionais. E muitos dos direitos começaram a ser flexibilizados através das reformas do Estado Mínimo.

Na educação, a Emenda Constitucional nº 14, que criou o Fundo de Manutenção e Desenvolvimento do Ensino Fundamental e de Valorização do Magistério (FUNDEF), suprimiu os esforços para erradicar o analfabetismo e para expandir e interiorizar as universidades públicas. O Estado passou a priorizar apenas uma etapa da educação escolar (Ensino Fundamental, de 7 a 14 anos), deixando a educação infantil, o ensino médio e a própria Universidade desamparados financeiramente.

Essa política de focalização do Ensino Fundamental, orientada por organismos internacionais para atender os princípios basilares do "capitalismo globalizado" - que concentrava (e ainda concentra) os meios de produção nas nações ricas, cabendo aos países periféricos atender a demanda por mão de obra com qualificação intermediária - passou por transformações no Brasil, a partir de 2006, com a promulgação das Emendas Constitucionais n. 53 e 59.

A EC 53 substituiu o FUNDEF pelo Fundo de Manutenção e Desenvolvimento da Educação Básica e de Valorização dos Profissionais da Educação (FUNDEB), instituído através de nova redação do art. 60 do Ato das Disposições Constitucionais Transitórias (ADCT). E o novo Fundo Público mudou a lógica do financiamento da escola pública, aumentando o percentual de subvinculação de impostos e transferências do artigo 212 da CF/1988 para toda a educação básica. Além de garantir financiamento público da creche ao ensino médio, o FUNDEB aumentou a participação da União no financiamento da escola de nível básico, passando de $\mathrm{R} \$ 450$ milhões, em 2006, para mais de $\mathrm{R} \$ 12$ bilhões em 2017 - apenas na forma de complementação ao Custo Aluno Anual do FUNDEB.

Já a EC 59 ampliou o ensino obrigatório de 4 a 17 anos (uma das maiores referências em nível mundial), pôs fim à Desvinculação de Receitas da União (DRU) na educação e, juntamente com investimento efetivo superior ao mínimo constitucional de $18 \%$, na esfera federal, o País mais que dobrou o número de Escolas Técnicas e de Institutos Federais de Educação, Ciência e Tecnologia, bem como inaugurou quase duas dezenas de novas universidades (18 no total) e mais de uma centena de novos campus universitários, retomando o compromisso original do art. 60 do ADCT. 
Os esforços por novos recursos para priorizar o acesso à escola e à universidade pública de qualidade foram mantidos por mais de uma década. $\mathrm{O}$ art. 214 da Constituição foi alterado pela EC 59 para permitir a vinculação dos investimentos educacionais a percentuais do Produto Interno Bruto (PIB) e, em 2014, o Congresso Nacional aprovou o Plano Nacional de Educação prevendo alcançar investimento na educação equivalente a $10 \%$ do PIB, até 2024. Dois anos antes, o mesmo Congresso tinha aprovado a Lei 12.858, repassando royalties e outras riquezas advindas da exploração de petróleo e gás para a educação. Em 2010, a Lei 12.351, que regulamentou a exploração do Pré-sal e que criou o Fundo Social, também havia vinculado recursos da exploração de hidrocarbonetos para a educação.

A partir de 2016, o Brasil vivencia um golpe institucional que depôs uma presidenta eleita democraticamente, sem que a mesma tivesse cometido qualquer crime de responsabilidade. E uma nova política de Estado Mínimo é implementada, em diversas áreas, inclusive na educação, comprometendo os objetivos originários da Carta Magna.

A EC 95, como destacado inicialmente, impôs o mais cruel ajuste fiscal à sociedade brasileira, ameaçando a oferta de serviços públicos em todo País. E, pela primeira vez, desde 1983 (ainda na vigência do regime militar), a vinculação de impostos da União para a educação (e a saúde) foi suspensa pelo governo golpista. Ou seja: por 20 anos, as políticas educacionais da União e suas parcerias com estados, DF e municípios não contarão com recursos novos, além da reposição inflacionária.

No mesmo sentido restritivo, após 2016, o Congresso Nacional reviu e continua revendo diversas leis que vinculavam recursos do petróleo e gás para a educação. A prioridade do governo federal voltou a ser o pagamento da dívida pública aos acionistas/rentistas, o que motivou a recente revogação do Fundo Soberano do Pré-Sal, por meio da Medida Provisória n. 830/2018.

A privatização do Pré-sal e a desoneração de impostos nas atividades de exploração do petróleo brasileiro, concedida às petrolíferas estrangeiras, alcançando a perda de mais de R $\$ 1$ trilhão, também inviabilizam o compromisso constitucional de maior alocação de recursos para a educação e outras políticas públicas voltadas à equidade social.

Os cortes nos orçamentos das Universidades e dos Institutos Federais de Educação, Ciência e Tecnologia seguem a dinâmica do ajuste fiscal (EC 95) e da reforma do Ensino Médio. Tentar-se-á enxugar as matrículas no ensino superior público através de menos recursos e de menor demanda provinda do nível básico escolar.

A reforma do Ensino Médio avança na desconstituição do direito à educação como dever do Estado, pois obriga as redes públicas a oferecerem apenas a parte da base nacional comum curricular (BNCC, de até 1.800 horas), podendo a maior parte do currículo ("conteúdos flexíveis", que alcançarão 2.400 horas após o ano de 2022) ser ofertada pela rede privada através de cursos de qualificação profissional ou mesmo contando horas de trabalhos voluntários ou de telecursos. 
Além de estimular a mercantilização, a privatização e o desemprego em massa de educadores do ensino médio (só as disciplinas de português e matemática serão de fato obrigatórias), a reforma institui verdadeiro apartheid socioeducacional, na medida em dificulta o acesso de estudantes das classes populares em universidades públicas, ao reduzir o conteúdo curricular nas escolas públicas.

No campo das liberdades individuais e de cátedra, asseguradas na CF/1988, muitos são os movimentos de poderes executivos, do Congresso Nacional e das casas legislativas subnacionais para flexibilizar ou mesmo suprimir comandos da Constituição. A Lei da Mordaça (Escola sem Partido) é a maior expressão do ataque à liberdade de aprender, ensinar, pesquisar e divulgar o pensamento, a arte e o saber e ao pluralismo de ideias e de concepções pedagógicas (art. 206, II e III da CF/1988).

Além das restrições de direitos impostas por emendas constitucionais conservadoras e neoliberais, há inúmeros dispositivos da CF/1988 que sequer foram regulamentados. A garantia do padrão de qualidade (art. 206, VII) por meio do Custo Aluno Qualidade e o piso salarial nacional para todos os profissionais da educação (art. 206, VIII) estão pendentes de análise pelo Congresso. A valorização dos profissionais da educação foi concebida pela metade, através de piso do magistério que não contempla os funcionários administrativos. Já as reformas neoliberais em curso possibilitam contratar profissionais sem concurso público por meio de contratos temporários, por notório saber ou mesmo por Organizações Sociais (OSs).

Outros ataques aos princípios republicanos de nossa Constituição e que visam privatizar fundos públicos estão em debate no Congresso, sob a orientação do governo Michel Temer. Destaque para a reforma da Previdência, que pretende estabelecer tempo de contribuição de mais de 40 anos para todos os trabalhadores e trabalhadoras (setores público e privado), estimulando a oferta de planos privados de previdência e concedendo a gestão de fundos públicos à rede particular.

Em meio a esse ataque desmedido do capital sobre os direitos da população e sobre as riquezas do País, a CONAPE se apresenta como importante espaço de reflexão e resistência, possibilitando a mobilização de diversos atores contra a agenda de retrocessos em curso no Brasil.

De outro lado, o Fórum Nacional Popular de Educação, responsável por organizar a CONAPE, também possui papel estratégico na organização do debate sobre os temas acima elencados, devendo o mesmo agregar mais organizações e, quiçá, se consolidar como espaço social de resistência ao direito à educação e de formulação das políticas públicas educacionais, enquanto perdurar o Golpe. 